\title{
Août 2021
}

\section{Cumulus sud-américains}

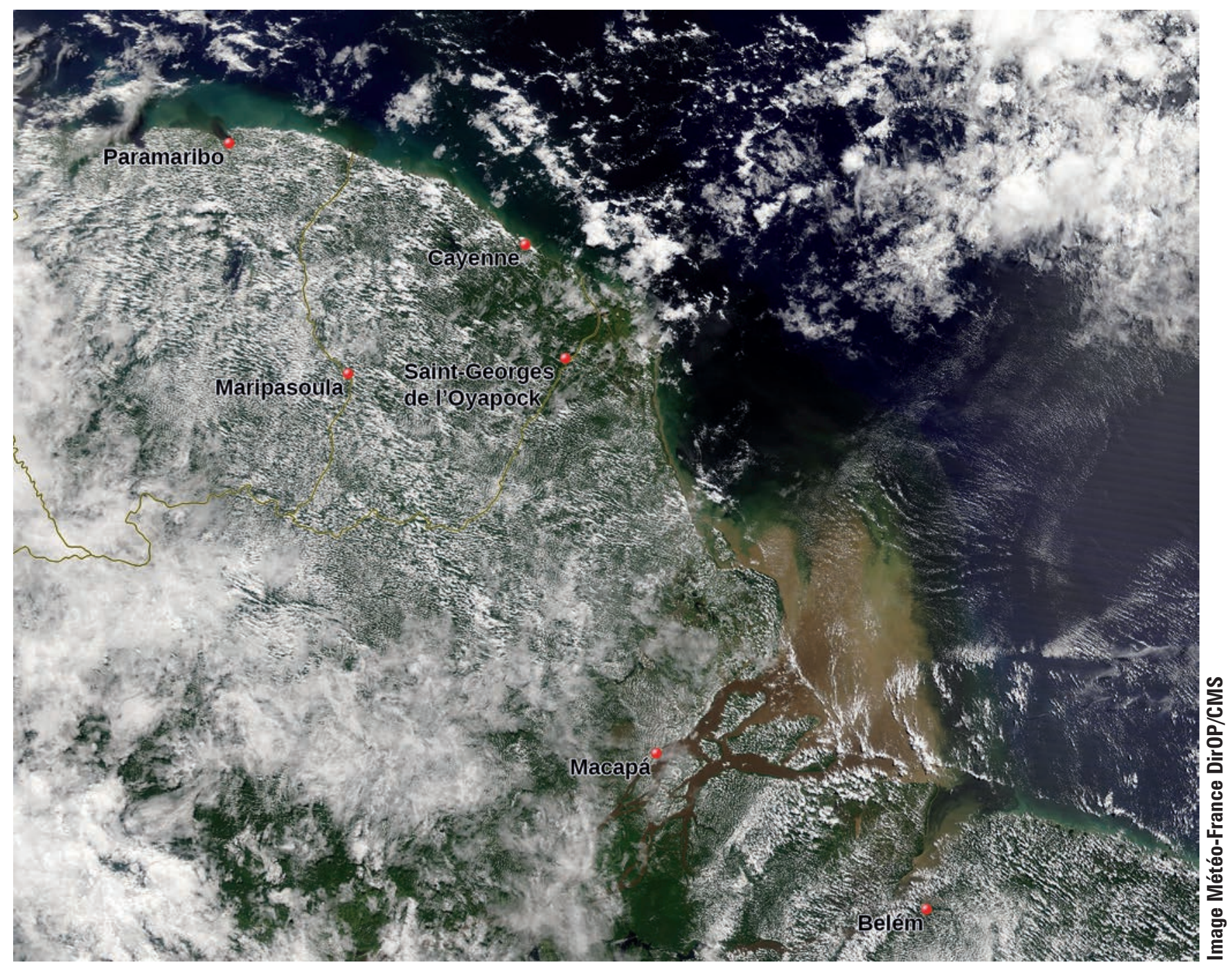

Terra - Le $1^{\text {er }}$ août 2021 à 13 h 45 TU - Image en vraies couleurs

a zone intertropicale de convergence $(Z I C)$ a la délicate attention de remonter vers le nord au début de - l'été et d'offrir à la Guyane une saison dite sèche de juillet à novembre. En effet, la ZIC se déplace en latitude au gré des saisons. Un alizé de sud-est s'installe, le ciel guyanais retrouve de franches pério des ensoleillées qui constituent un élément moteur pour le développement de cumulus d'évolution diurne. C'est le cas ici sur toute l'image, du Suriname au Brésil. À ce stade, ils ne donnent pas encore de précipitations, mais peuvent se transformer en quelques heures en cumulonimbus générateurs d'averses et d'orages. Du côté de M acapá, c'est l'Amazone qui attire notre œil. Son débit est tel que la salinité et la couleur de l'océan Atlantique sont modifiées jusqu'à 300 km des côtes. 

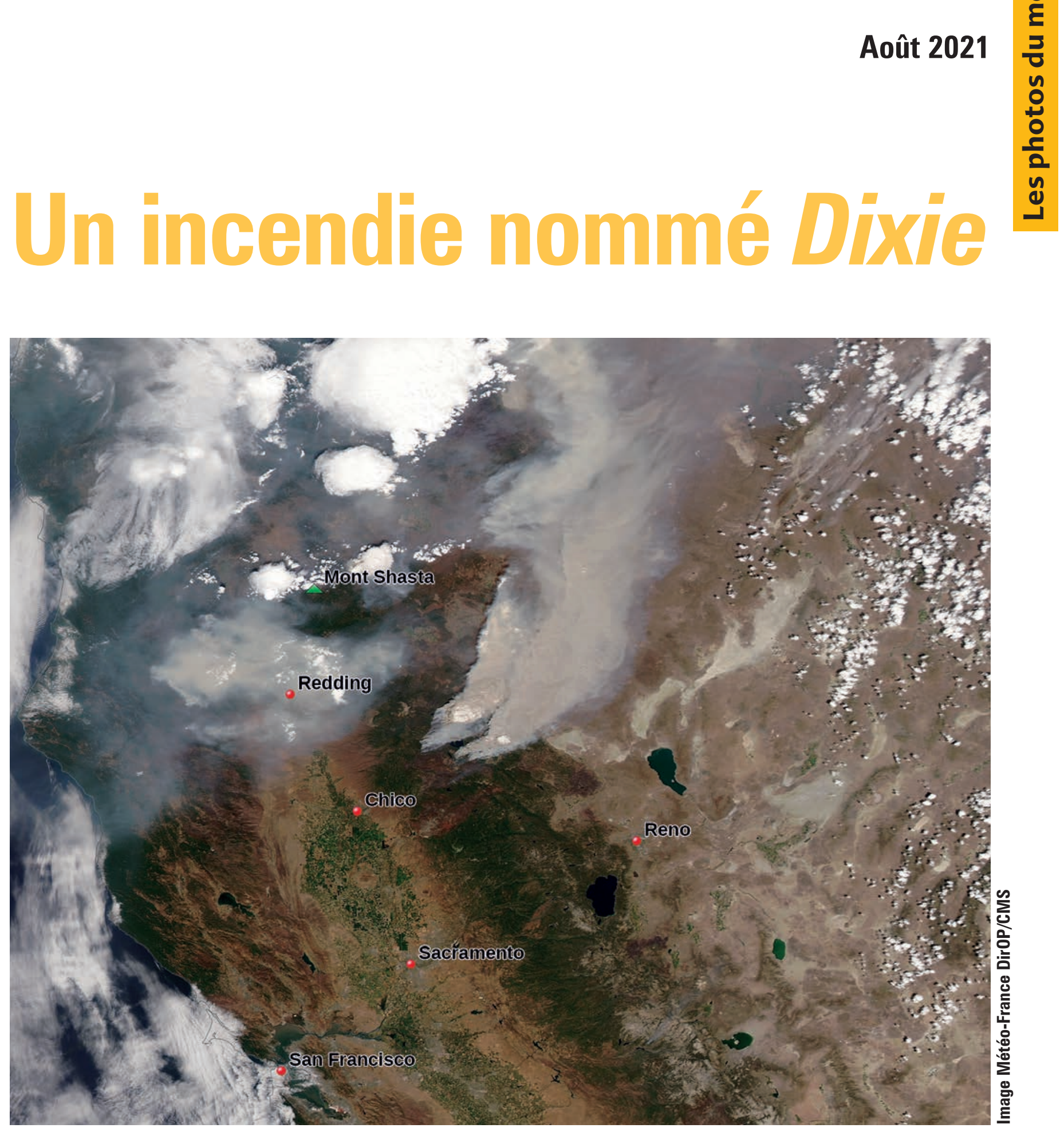

Aqua - Le 5 août 2021 à 21 h 25 TU - Image en vraies couleurs

ontrairement aux cyclones qui se voient attribuer des prénoms suivant une liste prédéfinie, les incendies américains tirent leur appellation de points de repère situés à proximité des lieux où ils ont démarré. Dans l'ouest des États-U nis, c'est la saison des feux comme on parle de la saison des cyclones en Floride. Au nord-est de Chico (Californie), Dixie fire est l'incendie le plus ravageur de l'été. Il éclate le 13 juillet et tire son nom d'une route située non loin des premiers foyers. Le 4 août, il rase en moins de deux heures la petite ville de $\mathrm{G}$ reenville. Attisé par de fortes chaleurs, une sécheresse alarmante et des vents changeants et soutenus, il est hors de contrôle. De plus, il est situé dans un endroit peu accessible. À la fin du mois d'août, il est toujours actif, laissant dans son sillage 275000 hectares ravagés. 